\title{
Tuning the optical and self-assembly properties of diketopyrrolopyrrole semicarbazone derivatives through hydrogen bonding
}

Swann Militzer, ${ }^{[a]}$ Thi My Phuong Tran, ${ }^{[a]}$ Philippe J. Mésini ${ }^{[a, b]}$ and Amparo Ruiz-Carretero*[a]

[a] University of Strasbourg, Institut Charles Sadron, CNRS, UPR22, 23 Rue du Loess, 67000

Strasbourg Cedex 2. E-mail: amparo.ruiz@ics-cnrs.unistra.fr

[b] International Center for Frontier Research in Chemistry, 8 allée Gaspard Monge, 67000 Strasbourg.

Abstract: Hydrogen bonds are great noncovalent interactions for guiding the self-assembly processes in organic semiconductors. Their presence into the molecular structures allows modifying their aggregation state by changing the solvent, concentration and temperature. Here we show that just by functionalizing simple thiophene-capped diketopyrrolopyrrole derivatives with semicarbazone units, the optical and self-assembly properties can be tuned while controlling the formation of hydrogen-bonding. The appearance of J-type aggregates upon hydrogen-bonding formation made possible to vary the energy band gaps and supramolecular structures formed in solution and on thin films.

$\pi$-Conjugated systems, polymers ${ }^{[1]}$ and small molecules, ${ }^{[2]}$ are extensively employed in the field of organic electronics. ${ }^{[3,4]}$ Both, the optoelectronic properties and the structural aspects of these systems have to be optimized to reach good performance in the final applications. The structures formed can be controlled by rational design ${ }^{[5]}$ or by applying different processing techniques. ${ }^{[6-9]}$ Supramolecular chemistry is an alternative to achieve such control, especially when using small molecules. This way, it is possible to build semiconducting systems where the electroactive motifs are precisely organized by noncovalent interactions into functional supramolecular polymers. ${ }^{[10,11]}$ The incorporation of highly directional noncovalent interactions, such as hydrogen bonds can guide the self-assembly processes and vary the electronic properties accordingly. Hydrogen bonds are sensitive to solvent, concentration and temperature. Furthermore, the number, position and strength can deeply impact the selfassembly processes, influencing the final properties. Hydrogen bonds have been used in several types of organic electronic devices, such as organic light emitting diodes (OLEDs), ${ }^{[12,13]}$ organic field effect transistors (OFETs) $)^{[14,15]}$ and solar cells. ${ }^{[16-21]}$ In these examples, the hydrogen bonds afforded better connection among semiconductors, and thus very appropriate structures for charge transport.

3,6-diaryl-2,5-dihydro-1,4-diketopyrrolo[3,4-c]pyrrole (DPP) ${ }^{[22,23]}$ has gained recently a lot of attention in the field of organic electronics due to its good electronic properties. ${ }^{\left[{ }^{24]}\right.}$ A plethora of DPP derivatives comprising small molecules ${ }^{[25]}$ and polymers ${ }^{[26]}$ have been studied. The simple DPP derivative having two thiophene rings is one of the most used starting materials to synthesize semiconducting polymers and oligomers. ${ }^{[27,28]}$ The optoelectronic and self-assembly properties of DPP derivatives mainly depend on the aromatic groups attached to the DPP core, and in many studies they are modified with electron-donating(withdrawing) groups are studied. ${ }^{[24,29]}$ Interestingly, the use of hydrogen bonding is a great tool to tune the optoelectronic and self-assembly properties of small DPP derivatives without enlarging the thiophene DPP core. The examples of hydrogen-bonded DPP found in literature usually utilize the non-alkylated version of the pyrrole rings, ${ }^{[14,30]}$ which normally are vacuum deposited due to insolubility or DPP oligomers modified in the peripheral positions with amide bonds. ${ }^{[17,31,32]}$ Here we show that it is possible to tune the optical properties and thin film morphology of simple thiophene-capped 
DPP derivatives functionalized with semicarbazone (Scheme 1). By changing the aggregation state of these simple DPP derivatives it was possible to reach the near infrared (NIR) region. Similar properties to the ones of semiconducting polymers and oligomers are obtained just by modifying the hydrogen bond aggregation state. DPP derivatives containing phenyl rings functionalized with semicarbazone units have been described as colorimetric chemosensors, ${ }^{[33]}$ but their self-assembly properties have not been studied. DPPSC derivative (Scheme 1) was synthesized following a reported protocol starting from a condensation reaction between 2thiophenecarbonitrile and diethylsuccinate ${ }^{[22]}$ and subsequent alkylation with ethylhexyl bromide (See the supporting information for details). With a Vilsmeier-Haack reaction an aldehyde functionality was introduced in one of the thiophenes. The formylated DPP intermedium was condensed with 4-phenylsemicarbazide to afford the final derivative DPPSC. Another brominated derivative (BrDPPSC) was also synthesized to study the influence of bromination and to show the possibility of further functionalization. The synthetic procedure was similar to the one of DPPSC but with an additional bromination step (Scheme 1). UV/vis spectroscopy studies were performed for both molecules in solution and as solids in thin films. Different solvents, concentration series and variable temperature measurements were performed to follow the self-assembly process of DPPSC and BrDPPSC. Chloroform is a good solvent for both compounds and no aggregation takes place. $2.5 \mathrm{mg} / \mathrm{ml}$ solutions in chloroform (Figure 1a and $1 \mathrm{~b}$, green traces and table 1) show broad absorption bands (450 to $650 \mathrm{~nm}$ ) in the visible with $\lambda_{\max }$ at $552 \mathrm{~nm}$ and $584 \mathrm{~nm}$ for DPPSC and $\lambda_{\max }$ at $557 \mathrm{~nm}$ and $594 \mathrm{~nm}$ for BrDPPSC. The vibronic structure of the absorption bands is typical of DPP dyes, but they present a red-shift compared to its analogue DPP without hydrogen-bonding motifs ${ }^{[24]}$ due to the electronwithdrawing nature of the semicarbazone unit. The formation of hydrogen-bonding was not detected in the absorption spectra at this concentration and it was demonstrated as well with Fourier transform infrared (FTIR) spectroscopy (Figure 1c). While the sample in solid state shows one signal in the $\mathrm{NH}$ stretching region typical of hydrogen-bonding, the sample in deuterated chloroform shows two bands corresponding to free $\mathrm{NH}$. The optical band gaps $\left(E_{g}\right)$ in solution were determined from the onsets of absorption at low energy, being $1.96 \mathrm{eV}$ and $1.90 \mathrm{eV}$ for DPPSC and BrDPPS, respectively. There is good correlation between the optical and the electrochemical band gaps (Figure S1 and table 1). In chlorobenzene and toluene, a bathochromic shift was observed for the two absorption maxima in both molecules. Interestingly, the appearance of a J-aggregate, where the hydrogen bonds are involved ${ }^{[34]}$ with centre at 630 $\mathrm{nm}$ and $665 \mathrm{~nm}$ was observed for both derivatives in chlorobenzene and toluene (Figure 1a and $1 \mathrm{~b}$, red and blue traces and Table 1). This aggregate signal was inexistent in chloroform at the same concentration and that could still be observed when the samples were heated up to 100 ${ }^{\circ} \mathrm{C}$ with lower intensity. This indicates that these solvents promote aggregation even at high temperature (Figure S2b, c, f and g). Such aggregates reach $800 \mathrm{~nm}$, expanding the absorbance to the NIR region and lowering the optical band gap to $1.77 \mathrm{eV}$ and $1.74 \mathrm{eV}$ for DPPSC and $1.74 \mathrm{eV}$ and $1.72 \mathrm{eV}$ for BrDPPSC in chlorobenzene and toluene, respectively. The appearance of such aggregate band is particularly interesting since it has been reported to be beneficial for device performance in organic solar cells ${ }^{[35]}$ and great exciton transporters. ${ }^{[36]}$ When the samples were diluted, the intensity of this band decreased until it totally disappeared (Figure S3). When DPPSC and BrDPPSC solutions were warmed up to temperatures close to the boiling point of the solvents, a hypsochromic shift and a variation in the intensity ratio of the vibronic peaks (0-0 and 0-1 transitions), were detected (Figure S2a-h). This effect has been observed previously in other DPP-based dyes without hydrogen bonds ${ }^{[35,37]}$ in the solid state. It can be related to the presence of two types of aggregates when the strength of the intermolecular excitonic coupling is similar to the electron-vibrational coupling. It has been reported $^{[38,39]}$ that $\mathrm{H}$ - and $\mathrm{J}$-aggregates can be distinguished by the decreasing $(\mathrm{H}-)$ or increasing (J-) ratio of the first two vibronic peak intensities. In all cases except for the solutions in chloroform, the $0-0 / 0-1$ vibronic peak ratio is smaller than unity at high temperature $\left(60^{\circ} \mathrm{C}\right.$ for 
chloroform and ethyl acetate and $100{ }^{\circ} \mathrm{C}$ for chlorobenzene and toluene) and larger than unity at $20^{\circ} \mathrm{C}$ (Figure S2a, b, c, e, $\mathrm{f}$ and $\mathrm{g}$ ). This is consistent with a predominant contribution of H-type aggregates at high temperatures, where the hydrogen bonds are weaker and $\pi-\pi$ stacking interactions govern the assemblies, and a predominant contribution of J-type aggregates at room temperature, where hydrogen bonds are stronger and involved in the formation of such types of aggregates. In the case of chloroform, the 0-0/0-1 transition is smaller than unity at 20 ${ }^{\circ} \mathrm{C}$ and $60^{\circ} \mathrm{C}$, indicating that $\mathrm{H}$-type aggregates are predominant and no hydrogen-bonding formation is detected (Figure S1a and e). To demonstrate the role of hydrogen bonds in the formation of this J-type aggregate, a small amount of methanol was added to disrupt the formation of hydrogen bonds. In fact, with $4 \%$ volume of methanol added to a $2.5 \mathrm{mg} / \mathrm{ml}$ solution in chlorobenzene and $6 \%$ volume in toluene for DPPSC and $4 \%$ in both solvents for BrDPPSC, the J-aggregate band disappeared and the absorption spectra resembled the ones in chloroform or the spectra in chlorobenzene and toluene in dilute conditions (Figure S4).

More pronounced changes were observed in ethyl acetate. In this solvent, a change in the vibronic structure is observed together with the increase in intensity of the J-aggregate, particularly strong in the case of BrDPPSC (Figure 1a and 1b, black traces). The absorption maxima appear at $546 \mathrm{~nm}$ and $577 \mathrm{~nm}$ for DPPSC and at $555 \mathrm{~nm}$ and $593 \mathrm{~nm}$ for BrDPPSC. For both derivatives, the J-aggregate band reaches the NIR region of the spectra and the intensity of the band decreased when increasing the temperature (Figure S2 $d$ and $h$ ), being the $0-0 / 0-1$ vibronic transition ratio below unity at $60^{\circ} \mathrm{C}$, indicating mostly the presence of $\mathrm{H}$-type aggregates. The optical band gap of DPPSC in this solvent is of $1.69 \mathrm{eV}$ and smaller for BrDPPSC, even though it was not calculated due to scattering. Interestingly, when BrDPPSC was heated to the boiling temperature of the solvent and cooled down to room temperature, a gel-like material was obtained (Figure S5), finding in this case the presence of $\mathrm{H}$ - and J-type aggregates. This is consistent with previous works on hydrogen-bonded organogelators based on oligothiophene and DPP. ${ }^{[16,31,34]}$ In this case, the presence of a bromine atom shows big differences in the assembly process. The J-aggregate also disappeared upon diluting the samples in ethyl acetate and spectra were also taken upon addition of methanol and as expected, a larger volume of methanol was needed to disrupt the hydrogen-bonding formation (Figure $2 \mathrm{a}$ and $2 \mathrm{~b}$ ), being particularly large in the case of BrDPPSC (21\%). For both derivatives, the absorption spectra presented a change in intensity of the vibronic peaks, being the 0-0/0-1 transition below unity once the hydrogen bonds are disrupted and the J-aggregate band disappears. Even though the band gaps found in ethyl acetate are very small and could be detrimental for device performance, they could be tuned by addition of methanol until reaching the desired value. Furthermore, both derivatives could be used in ethyl acetate as NIR absorbing additives to enhance device performance, ${ }^{[40]}$ since this solvent is described as one of the greenest for device processing. ${ }^{[41]}$

The absorption spectra of DPPSC and BrDPPSC on thin spin coated films were recorded and they differ in all cases from the spectra in solution (Figure 1d, 1e and Figure S6 and S7). A bathochromic shift is observed as a consequence of stronger intermolecular interactions in the solid state together with an increase in intensity of the J-aggregate respect to the samples in solution (Figure S6 and S7). In the case of DPPSC, the thin films prepared in all solvents presented an absorption spectrum very similar to the spectrum of DPPSC in ethyl acetate solution (Figure 1a and 1d) with increasing intensity of the J-type aggregate. The optical energy band gaps in the solid state are in the range of 1.77-1.50 eV for DPPSC. On the other hand, the spectra of BrDPPSC on thin film prepared from chloroform, chlorobenzene and toluene show absorption similar to the ethyl acetate solution (Figure $1 \mathrm{~b}$ and 1e), except for the film in the latter solvent, where the absorption was red-shifted, increasing the intensity of the J-aggregate band and indicating that the formation of hydrogen bonds is predominant (Figure 1e, black trace).

Thin film morphology of DPPSC and BrDPPSC were studied using scanning electron microscopy (SEM), finding different structures in all solvents (Figure $3 a-h)$. This will be 
particularly interesting to study the influence of different morphologies in device performance and to study charge transport using different structures. Long aspect-ratio structures were observed in all cases, finding nanofibers in chloroform, needle-like structures, nanobelts and nanotapes with widths in the order of nanometers and lengths of tens of micrometers. Hydrogen-bonding plays a leading role in the formation of the supramolecular structures since when samples made from solutions containing methanol were studied, a change in morphology was observed. Interestingly, fiber-like structures of much shorter length were found in all solvents with totally different shape (Figure 4a-f). Even the nanobelts observed in ethyl acetate samples were disrupted resulting in needle-like structures with shorter length.

In summary, two DPP derivatives containing semicarbazone have been synthesized and their optical and self-assembly properties have been studied. The formation of hydrogen bonds resulted in the appearance of J-aggregates, being possible to tune the bandgap and cover larger regions of the solar spectrum by modifying the aggregation state with different solvents, concentrations, temperature or the addition of hydrogen-bonding disrupting solvents. Future directions will be devoted to study charge transport and device performance at different aggregation states.

\section{Acknowledgements}

The authors acknowledge the characterization facility for UV-Vis and FTIR and the microscopy platform for the use of SEM of Insitut Charles Sadron (CNRS). A. R. C. thanks the University of Strasbourg (IdEx investissement 2016) and CNRS (PEPS Energie 2016) for financial support. S. M. thanks the International Research Training Center (IRTG) SoMas and the Région GrandEst for the doctoral fellowship. The authors gratefully acknowledge Jean-Philippe Lamps for laboratory technical support.

Keywords: supramolecular chemistry • diketopyrrolopyrrole • hydrogen bonds $\bullet$ self-assembly •

Figures

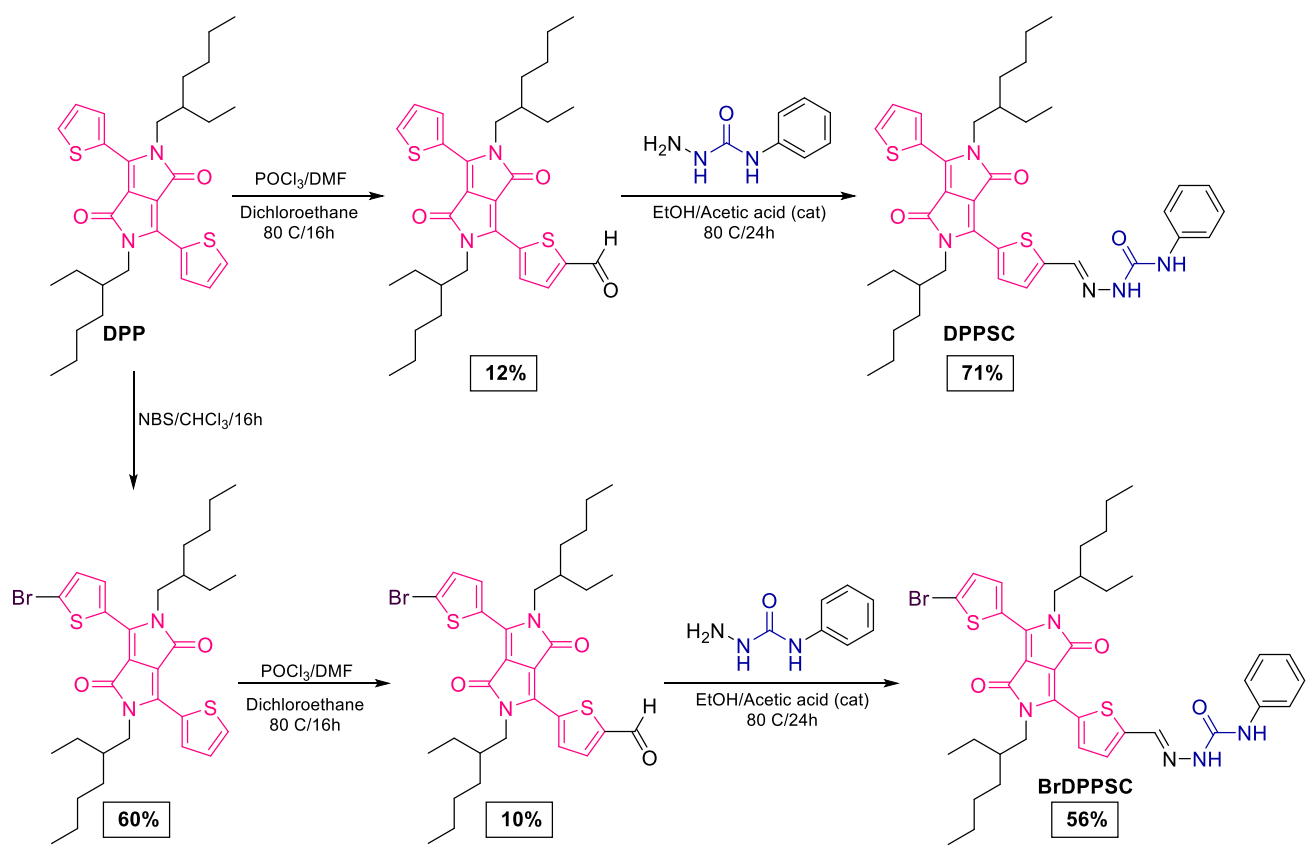

Scheme 1. Synthetic steps towards DPPSC and BrDPPSC derivatives. 
a)

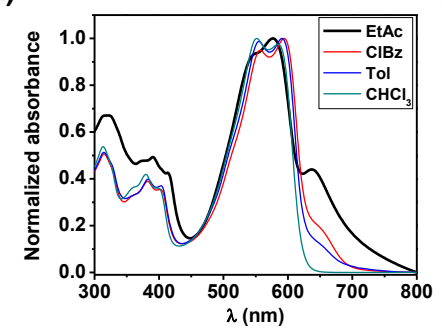

d)

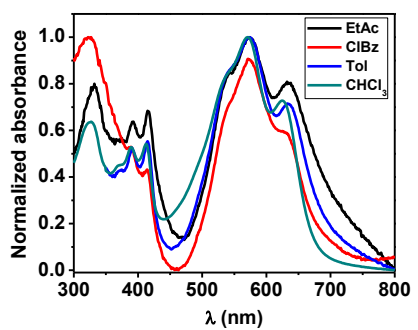

b)

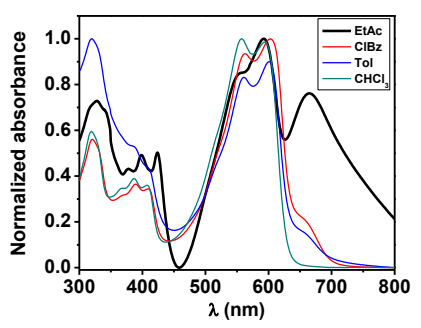

e)

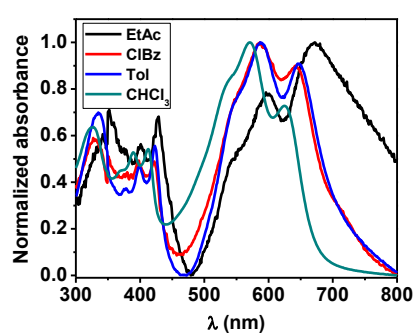

c)

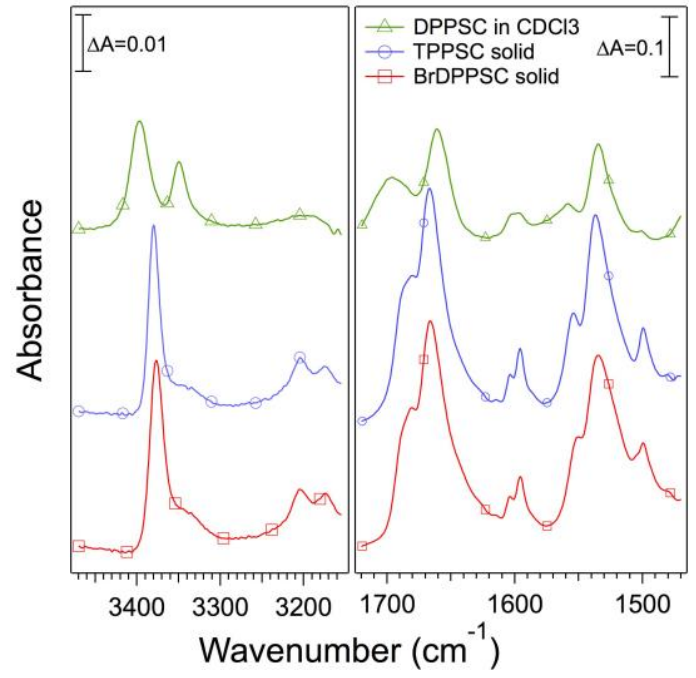

Figure 1. Normalized absorption spectra in solution of DPPSC (a) and (b) BrDPPC. [DPPSC] = $[$ BrDPPSC $]=2.5 \mathrm{mg} / \mathrm{ml}$. Normalized absorption spectra on spin coated thin films (2000 rpm) of DPPSC (d) and (e) BrDPPSC. [DPPSC] $=[$ BrDPPSC] $=2.5 \mathrm{mg} / \mathrm{ml}$. Fourier transform infrared (FTIR) spectra in solid state and solution in deuterated chloroform of DPPSC and FTIR spectra in solid state of DPPSC and BrDPPSC (c).

a)

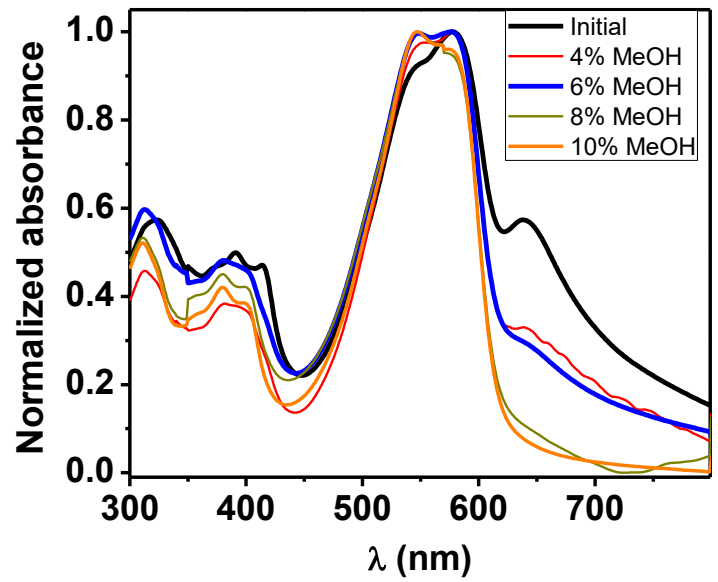

b)

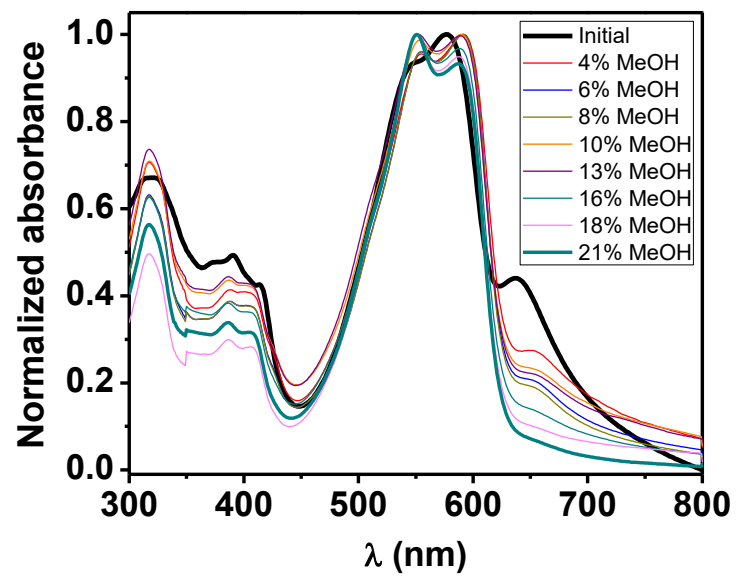

Figure 2. Normalized absorption spectra in solution of DPPSC (a) and (b) BrDPPC upon the addition of methanol. [DPPSC $]=[$ BrDPPSC $]=2.5 \mathrm{mg} / \mathrm{ml}$. 
Table 1. Optoelectronic properties

\begin{tabular}{|c|c|c|c|c|c|c|c|c|}
\hline & Solvent & $\begin{array}{c}\lambda_{\max }^{a b s, s o l} \\
{[\mathrm{~nm}]}\end{array}$ & $\begin{array}{c}\lambda_{\max }^{a b s, f i l m]} \\
{[\mathrm{nm}]}\end{array}$ & $\begin{array}{c}\mathrm{E}_{\mathrm{g}}^{\mathrm{opt}, \mathrm{sol}} \\
{[\mathrm{eV}]}\end{array}$ & $\begin{array}{c}E_{g}^{o p t, ~ f i l m ~} \\
{[\mathrm{eV}]}\end{array}$ & $\begin{array}{c}\mathrm{E}_{\mathrm{HOMO}}{ }^{[\mathrm{a}]} \\
{[\mathrm{eV}]}\end{array}$ & $\begin{array}{c}\mathrm{E}_{\text {LUMO }}{ }^{\mathrm{b}]} \\
{[\mathrm{eV}]}\end{array}$ & $\begin{array}{c}\mathrm{E}_{\mathrm{g}}{ }^{\mathrm{CV}[\mathrm{c}]} \\
{[\mathrm{eV}]}\end{array}$ \\
\hline \multirow{4}{*}{ DPPSC } & Chloroform & $\begin{array}{c}504(\mathrm{~s}), \\
552,584\end{array}$ & $\begin{array}{c}533,571 \\
624 \\
\end{array}$ & $1.96^{l}$ & 1.77 & \multirow{4}{*}{-5.18} & \multirow{4}{*}{-3.43} & \multirow{4}{*}{1.75} \\
\hline & Chlorobenzene & $\begin{array}{c}510(\mathrm{~s}) \\
556,595 \\
660\end{array}$ & $\begin{array}{c}535,572 \\
633 \\
\end{array}$ & 1.77 & 1.67 & & & \\
\hline & Toluene & $\begin{array}{c}505(\mathrm{~s}) \\
555,591 \\
654\end{array}$ & $\begin{array}{c}535,572 \\
634 \\
\end{array}$ & 1.74 & 1.65 & & & \\
\hline & Ethyl Acetate & $\begin{array}{c}546,577 \\
\quad 638\end{array}$ & $\begin{array}{c}539,576 \\
633 \\
\end{array}$ & 1.69 & 1.50 & & & \\
\hline \multirow{4}{*}{ BrDPPSC } & Chloroform & $\begin{array}{c}510(\mathrm{~s}), \\
557,594\end{array}$ & $\begin{array}{c}534,570 \\
\quad 625\end{array}$ & 1.90 & 1.73 & \multirow{4}{*}{-5.26} & \multirow{4}{*}{-3.5} & \multirow{4}{*}{1.76} \\
\hline & Chlorobenzene & $\begin{array}{c}510(\mathrm{~s}) \\
562,602 \\
663\end{array}$ & $\begin{array}{c}545,587 \\
643\end{array}$ & 1.74 & 1.50 & & & \\
\hline & Toluene & $\begin{array}{c}509(\mathrm{~s}) . \\
561,601 \\
667\end{array}$ & $\begin{array}{c}545,587 \\
\quad 647\end{array}$ & 1.72 & 1.50 & & & \\
\hline & Ethyl Acetate & $\begin{array}{c}555,593 \\
\quad 665\end{array}$ & $\begin{array}{c}541,597 \\
672\end{array}$ & $<1.5$ & $<1.5$ & & & \\
\hline
\end{tabular}

[a] Calculated from the onset of the first oxidation wave in dichloromethane. $E_{\text {номо }}=-4.8+\left(0.49-E_{\text {ox }}\right) \cdot 4.8$ is the energy level of ferrocene under the vacuum level. [b] Calculated from the onset of the first reduction wave in dichloromethane. $E_{\mathrm{LUMO}}=-4.8+(0.49-$

$\left.\mathrm{E}_{\mathrm{red}}\right)$ [c] Calculated from the difference between the highest occupied molecular orbital (HOMO) and the lowest unoccupied molecular orbital (LUMO). 

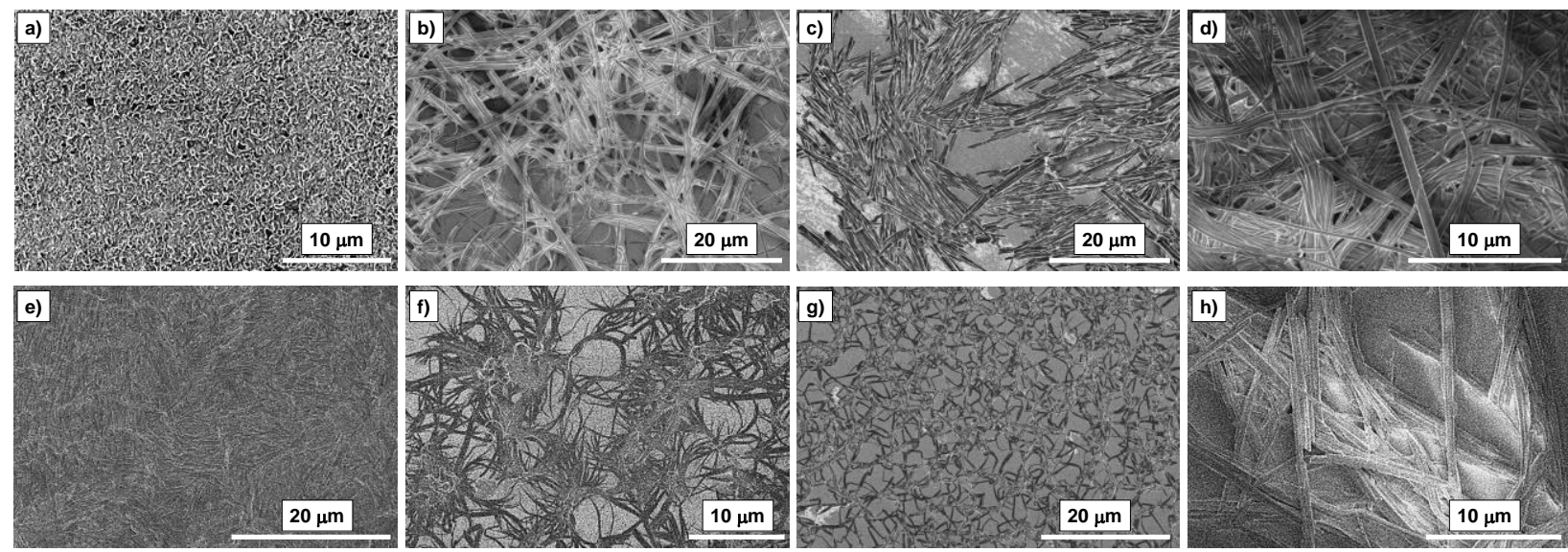

Figure 3. SEM images of thin films made by spin coating solutions at $2000 \mathrm{rpm}$ of DPPSC in a) chloroform, b) chlorobenzene, c) toluene, d) ethyl acetate and BrDPPSC in e) chloroform, f) chlorobenzene, g) toluene, $\mathrm{h}$ ) ethyl acetate. $[$ DPPSC $]=[$ BrDPPSC $]=2.5 \mathrm{mg} / \mathrm{ml}$.
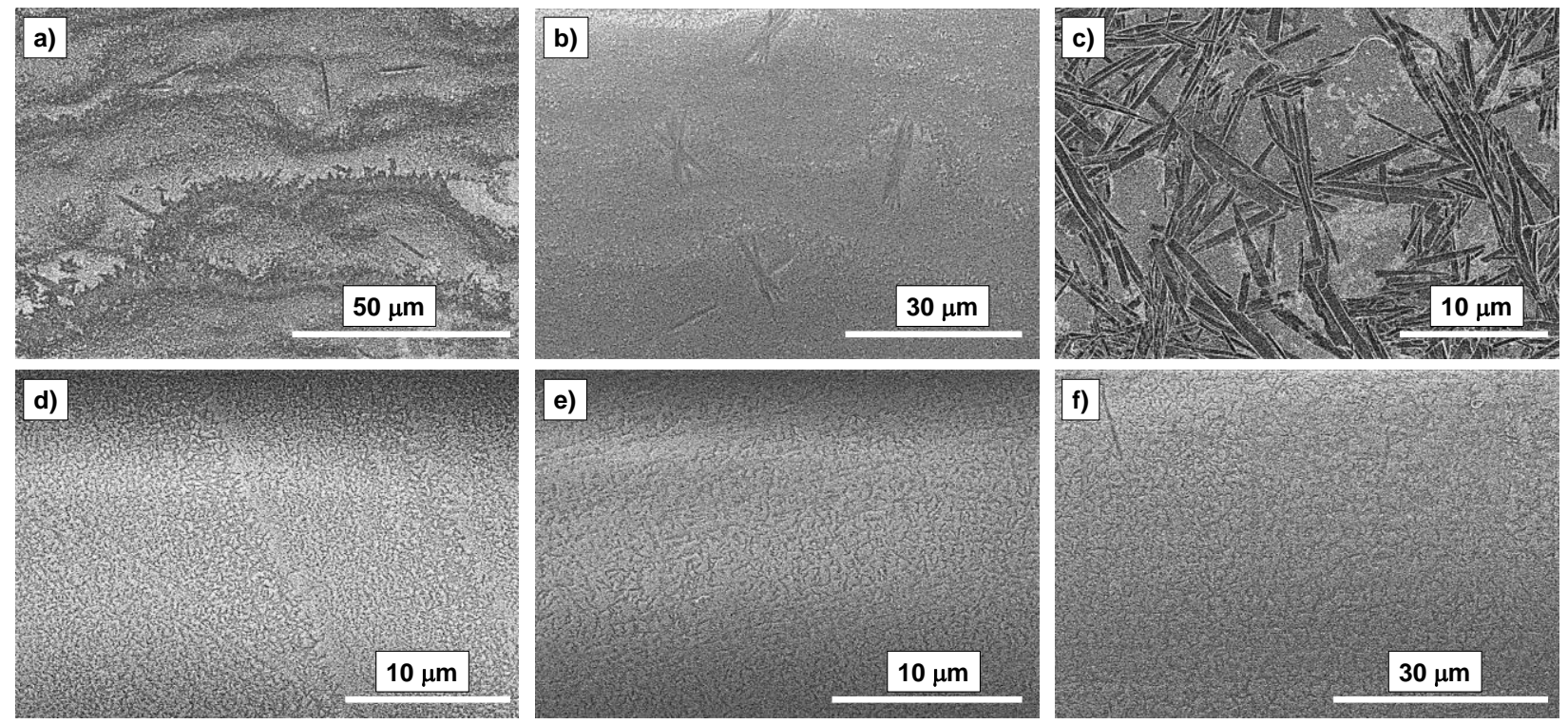

Figure 4. SEM images of thin films made by spin coating solutions in different solvents after the addition of methanol. DPPSC in a) chlorobenzene, b) toluene, c) ethyl acetate, and BrDPPSC in d) chlorobenzene, e) toluene, f) ethyl acetate. [DPPSC $]=[$ BrDPPSC $]=2.5 \mathrm{mg} / \mathrm{ml}$.

\section{References}

[1] A. Facchetti, Chem. Mater. 2011, 23, 733-758.

[2] S. D. Collins, N. A. Ran, M. C. Heiber, T.-Q. Nguyen, Adv. Energy Mater. 2017, 1602242.

[3] E. Moulin, E. Busseron, N. Giuseppone, in RSC Smart Mater. (Ed.: N. Koch), Royal Society Of Chemistry, Cambridge, 2014, pp. 152.

[4] C. R. Poelking, in Non-Local Density States Electron. Excit. Org. Semicond., Springer, Cham, 2018, pp. 1-11.

[5] B. McDearmon, Z. A. Page, M. L. Chabinyc, C. J. Hawker, J. Mater. Chem. C 2018, 6, 3564-3572.

[6] S. Steinberger, A. Mishra, E. Reinold, J. Levichkov, C. Uhrich, M. Pfeiffer, P. Bäuerle, Chem. Commun. 2011, 47, 1982.

[7] M. Babics, R. Z. Liang, K. Wang, F. Cruciani, Z. Kan, M. Wohlfahrt, M. C. Tang, F. Laquai, P. M. Beaujuge, Chem Mater Presss n.d., DOI 10.2021/acs.chemmater.7b04286.

[8] N. Stingelin, Polym. Int. 2012, 61, 866-873.

[9] Biniek Laure, Hamidi-Sakr Amer, Grodd Linda, Escoubas Stéphanie, Dappe Yannick J., Grigorian Souren, Schmutz Marc, Brinkmann Martin, Adv. Electron. Mater. 2018, 0, 1700480. 
[10] T. Aida, E. W. Meijer, S. I. Stupp, Science 2012, 335, 813-817.

[11] L. Brunsveld, B. J. B. Folmer, E. W. Meijer, R. P. Sijbesma, Chem. Rev. 2001, 101, 4071-4098.

[12] Watanabe Yuichiro, Sasabe Hisahiro, Yokoyama Daisuke, Beppu Teruo, Katagiri Hiroshi, Pu Yong-Jin, Kido Junji, Adv. Opt. Mater. 2015, 3, 769-773.

[13] R.-H. Chien, C.-T. Lai, J.-L. Hong, J. Phys. Chem. C 2011, 115, 12358-12366.

[14] E. D. Głowacki, H. Coskun, M. A. Blood-Forsythe, U. Monkowius, L. Leonat, M. Grzybowski, D. Gryko, M. S. White, A. Aspuru-Guzik, N. S. Sariciftci, Org. Electron. 2014, 15, 3521-3528.

[15] M. Irimia-Vladu, E. D. Głowacki, P. A. Troshin, G. Schwabegger, L. Leonat, D. K. Susarova, O. Krystal, M. Ullah, Y. Kanbur, M. A. Bodea, et al., Adv. Mater. 2012, 24, 375-380.

[16] A. Ruiz-Carretero, T. Aytun, C. J. Bruns, C. J. Newcomb, W.-W. Tsai, S. I. Stupp, J. Mater. Chem. A 2013, 1, 11674.

[17] T. Aytun, L. Barreda, A. Ruiz-Carretero, J. A. Lehrman, S. I. Stupp, Chem. Mater. 2015, 27, 1201-1209.

[18] H. Ouchi, X. Lin, T. Kizaki, D. D. Prabhu, F. Silly, T. Kajitani, T. Fukushima, K. Nakayama, S. Yagai, Chem. Commun. 2016, 52, 7874-7877.

[19] D. M. Bassani, L. Jonusauskaite, A. Lavie-Cambot, N. D. McClenaghan, J.-L. Pozzo, D. Ray, G. Vives, Coord. Chem. Rev. 2010, 254, 2429-2445.

[20] R. J. Kumar, J. Subbiah, A. B. Holmes, Beilstein J. Org. Chem. 2013, 9, 1102-1110.

[21] Z. Xiao, K. Sun, J. Subbiah, S. Ji, D. J. Jones, W. W. H. Wong, Sci. Rep. 2014, 4, DOI 10.1038/srep05701.

[22] A. Iqbal, M. Jost, R. Kirchmayr, J. Pfenninger, A. Rochat, O. Wallquist, Bull. Soc. Chim. Belg. 1988, 97, 615-644.

[23] Z. Hao, A. Iqbal, Chem. Soc. Rev. 1997, 26, 203-213.

[24] H. Bürckstümmer, A. Weissenstein, D. Bialas, F. Würthner, J. Org. Chem. 2011, 76, 2426-2432.

[25] A. Tang, C. Zhan, J. Yao, E. Zhou, Adv. Mater. 2017, 29, 1600013.

[26] W. Li, K. H. Hendriks, M. M. Wienk, R. A. J. Janssen, Acc. Chem. Res. 2016, 49, 78-85.

[27] A. B. Tamayo, M. Tantiwiwat, B. Walker, T. Q. Nguyen, J. Phys. Chem. C 2008, 112, 15543-15552.

[28] Y. Zou, D. Gendron, R. Neagu-Plesu, M. Leclerc, Macromolecules 2009, 42, 6361-6365.

[29] O. P. Lee, A. T. Yiu, P. M. Beaujuge, C. H. Woo, T. W. Holcombe, J. E. Millstone, J. D. Douglas, M. S. Chen, J. M. J. Fréchet, Adv. Mater. 2011, 23, 5359-5363.

[30] H. Yanagisawa, J. Mizuguchi, S. Aramaki, Y. Sakai, Jpn. J. Appl. Phys. 2008, 47, 4728.

[31] S. Ghosh, S. Cherumukkil, C. H. Suresh, A. Ajayaghosh, Adv. Mater. 2017, 29, 1703783.

[32] G. S. Thool, K. Narayanaswamy, A. Venkateswararao, S. Naqvi, V. Gupta, S. Chand, V. Vivekananthan, R. R. Koner, V. Krishnan, S. P. Singh, Langmuir 2016, 32, 4346-4351.

[33] X. Yang, L. Zheng, L. Xie, Z. Liu, Y. Li, R. Ning, G. Zhang, X. Gong, B. Gao, C. Liu, et al., Sens. Actuators B Chem. 2015, $207,9-24$

[34] W.-W. Tsai, I. D. Tevis, A. S. Tayi, H. Cui, S. I. Stupp, J. Phys. Chem. B 2010, 114, 14778-14786.

[35] M. Más-Montoya, R. A. J. Janssen, Adv. Funct. Mater. 2017, 27, DOI 10.1002/adfm.201605779.

[36] F. Würthner, T. E. Kaiser, C. R. Saha-Möller, Angew. Chem. Int. Ed. 2011, 50, 3376-3410.

[37] M. Kirkus, L. Wang, S. Mothy, D. Beljonne, J. Cornil, R. A. J. Janssen, S. C. J. Meskers, J. Phys. Chem. A 2012, 116, $7927-7936$.

[38] N. J. Hestand, F. C. Spano, Chem. Rev. 2018, DOI 10.1021/acs.chemrev.7b00581.

[39] F. C. Spano, Acc. Chem. Res. 2010, 43, 429-439.

[40] S. K. M. Nalluri, N. Shivarova, A. L. Kanibolotsky, M. Zelzer, S. Gupta, P. W. J. M. Frederix, P. J. Skabara, H. Gleskova, R. V. Ulijn, Langmuir 2014, 30, 12429-12437.

[41] C. McDowell, G. C. Bazan, Curr. Opin. Green Sustain. Chem. 2017, 5, 49-54. 


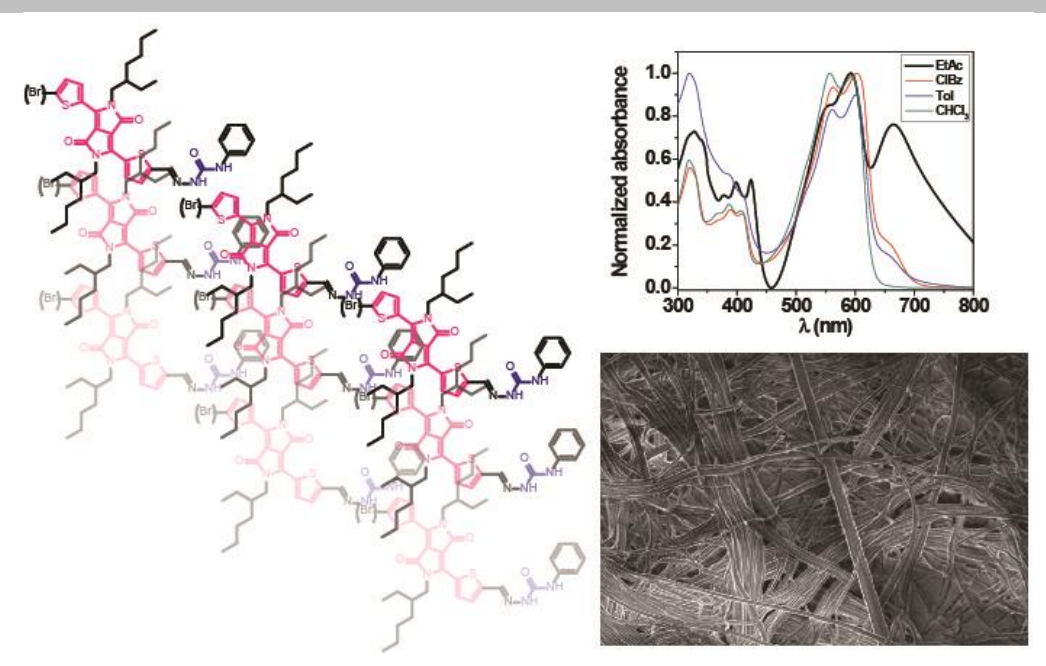

Swann Militzer, Thi My Phuong Tran, Philippe Mèsini, Amparo Ruiz-Carretero*

Page No. - Page No.

Tuning the optical and self-assembly properties of diketopyrrolopyrrole semicarbazone derivatives through hydrogen bonding

The incorporation of semicarbazone units in thiophene-capped diketorrolopyrrole small molecules allows to tune the optical and self-assembly properties by controlling the aggregation through hydrogen-bonding. The use of different solvents, concentration and temperature allows to tune the energy band gap and the thin film morphology. The appearance of J-type aggregates shifts the absorption up to the NIR, making possible to choose the most optimal conditions for future device fabrication. 